\title{
Article \\ Genome-Wide Identification and Analysis of Nilaparvata lugens microRNAs during Challenge with the Entomopathogenic Fungus Metarhizium anisopliae
}

\author{
Jiaqin Xie ${ }^{1,2, *} \mathbb{C}$, Yifan Peng ${ }^{1,2}$ and Yuxian Xia ${ }^{1,2, *}$ \\ 1 Genetic Engineering Research Center, School of Life Sciences, Chongqing University, \\ Chongqing 401331, China; pyifan@yeah.net \\ 2 Chongqing Engineering Research Center for Fungal Insecticides and Key Laboratory of Gene Function and \\ Regulation Technology under Chongqing Municipal Education Commission, Chongqing 401331, China \\ * Correspondence: xiejqin@cqu.edu.cn (J.X.); yuxianxia@cqu.edu.cn (Y.X.)
}

check for updates

Citation: Xie, J.; Peng, Y.; Xia, Y. Genome-Wide Identification and Analysis of Nilaparvata lugens microRNAs during Challenge with the Entomopathogenic Fungus Metarhizium anisopliae. J. Fungi 2021, 7, 295. https://doi.org/10.3390/jof7040295

Academic Editor: David Perlin

Received: 16 March 2021

Accepted: 13 April 2021

Published: 14 April 2021

Publisher's Note: MDPI stays neutral with regard to jurisdictional claims in published maps and institutional affiliations.

Copyright: (c) 2021 by the authors. Licensee MDPI, Basel, Switzerland. This article is an open access article distributed under the terms and conditions of the Creative Commons Attribution (CC BY) license (https:// creativecommons.org/licenses/by/ $4.0 /)$.

\begin{abstract}
The resistance of the notorious rice pest Nilaparvata lugens to many insecticides has caused significant concerns. Our previous study demonstrated that the fungus Metarhizium anisopliae CQMa421 shows great potential for the control of this pest, but the interactions between them are still unclear. Thus, we further investigated fungal infection-related microRNAs (miRNAs) in N. lugens during M. anisopliae CQMa421 challenge using Illumina sequencing. In this study, we constructed twenty-four small RNA libraries over different time courses (i.e., $4 \mathrm{~h}, 8 \mathrm{~h}, 16 \mathrm{~h}$, and $24 \mathrm{~h}$ ). A total of $478.62 \mathrm{M}$ clean reads were collected, with each sample producing more than $13.37 \mathrm{M}$ reads, after the removal of low-quality reads. We identified 2324 miRNAs and their 11,076 target genes within the twenty-four libraries by bioinformatics analysis. Differentially expressed miRNAs (DEmiRNAs), including 58 (32 upregulated vs. 26 downregulated), 62 (30 upregulated vs. 32 downregulated), 126 (71 upregulated vs. 55 downregulated), and 109 (40 upregulated vs. 69 downregulated) DEmiRNAs were identified at $4 \mathrm{~h}, 8 \mathrm{~h}, 16 \mathrm{~h}$, and $24 \mathrm{~h}$ post-infection, respectively. We further conducted Gene Ontology (GO) and Kyoto Encyclopedia of Genes and Genomes (KEGG) pathway analysis to predict the functions of all target genes of DEmiRNAs. These DEmiRNAs targets identified during $24 \mathrm{~h}$ of infection were primarily involved in energy metabolism, lysine degradation, the FoxO signaling pathway, ubiquitin-mediated proteolysis, the mRNA surveillance pathway, and the MAPK signaling pathway. Taken together, our results provide essential information for further study of the interactions between the entomopathogenic fungus M. anisopliae and N. lugens at the posttranscriptional level.
\end{abstract}

Keywords: entomopathogenic fungus; Metarhizium anisopliae; fungal infection; Nilaparvata lugens; microRNAs; pest control

\section{Introduction}

The rice planthopper Nilaparvata lugens is one of the prominent insect pests associated with rice growth and production [1,2]. The area affected by rice planthoppers in China reached 23 million ha. in 2020 alone. This pest not only sucks the phloem sap of rice plants, causing direct damage [3], but also transmits plant viruses such as rice grassy stunt virus, resulting in indirect damage to rice plants [4]. Currently, the most common and effective approaches for the control of this pest depend on the use of chemical insecticides, whereas the misuse of insecticides has contributed undesirable effects on the ecological environment and nontargets as well as human health $[5,6]$. This species also rapidly develops resistance, adapting to insecticides after several generations, thus resulting in resurgence [1,7]. Transgenic rice varieties and approaches such as RNAi have been developed for insect pest control and achieved some success, but these methods are limited in terms of their effectiveness and availability for field applications [8-10]. Thus, more effective alternative 
approaches are needed to replace/reduce the use of chemical insecticides for pest control, especially under field conditions.

Entomopathogenic fungi are one of most important factors regulating the insect populations under natural conditions [11,12]. In contrast to the side effects of chemical insecticides, insects do not easily become resistant to fungal infection, which also poses lower risks to the environment and human health [11]. Several entomopathogenic fungal strains have been isolated from natural hosts and used for the control of some insect pests. For instance, two important fungal agents, Metarhizium anisopliae and Beauveria bassiana, showed good potential against insect pests such as Locusta migratoria [13], Alphitobius diaperinus [14], Chironomus riparius [15], and Helicoverpa armigera [16]. Additionally, a few specific M. anisopliae strains can be used against insecticide-resistant pests [17]. The engineered fungal strains transformed with genes encoding products such as an insecticidal scorpion toxin (Bj $\alpha$ IT) and Manduca sexta diuretic hormone (MSDH) showed improved virulence for the target pests $[18,19]$. The combined use of $M$. anisopliae and RNAi can affect the reproduction of $N$. lugens and has shown good potential for the control of this pest [20]. In our previous study, we found that the fungus M. anisopliae CQMa421 exhibited great potential for the control of major rice pests, including the rice planthopper N. lugens [21]. This fungal agent can also suppress the population of rice planthoppers to a low level under field conditions [22,23]. However, the underlying molecular interactions between the rice planthopper and the fungus are poorly understood, although this knowledge may enhance potential fungal agents for other pest control.

MicroRNAs (miRNAs) are a class of small noncoding RNAs consisting of $\sim 22 \mathrm{nu}-$ cleotides, including small interfering RNAs (siRNAs) and piwi-interacting RNAs (piRNAs) $[24,25]$. These miRNAs are common in plants, insects, and microbes and play crucial roles in regulating gene expression at the posttranscriptional level [26-28]. Many studies have reported that miRNAs can affect diverse physiological processes in organisms, such as development [29], metamorphosis [30,31], sexual divergence [32], and wing polyphenism development [33,34]. On the other hand, the uncontrolled expression of miRNAs may result in undesirable results, such as disease, unusual phenotype variation, or death [35]. With the ongoing development of sequencing technologies, miRNAs have been evaluated in many insect species under different conditions, including responses to stressful treatments or pathogenic challenges, which have provided important information for investigating the roles of miRNAs in regulating their target mRNAs [36-38]. These data also facilitate the development of new approaches for pest control in terms of providing potential target genes for both RNAi technology and the development of engineered fungus.

In a previous study, we evaluated the potential of $M$. anisopliae to infect the rice pest $N$. lugens adults and nymphs [21]. A large scale application of this fungal agent may also suppress the pest populations under field conditions, indicating that it can be employed as an alternative to chemical insecticides [23]. Although a few studies have reported the mRNA responses of such pests to different challenges, including insecticides, temperature stress, or different developmental conditions, the levels of fungus-induced miRNAs in these pests have scarcely been studied [39-41]. However, the study of miRNAs is crucial to reveal the interactions between the fungus and the insect host at the posttranscriptional level. Thus, we further examined the resulting miRNAs of $N$. lugens in response to $M$. anisopliae infection during different periods by transcriptomic analysis. This investigation may provide new insights for further study of insect host responses to entomopathogens at the posttranscriptional level and understand the molecular mechanisms of fungal infection.

\section{Methods and Materials}

\subsection{Insect and Sample Collection}

The N. lugens insects used in this study were obtained from our insectary (Plant Experimental Base at Chongqing University, Chongqing, China). The population of N. lugens was maintained on fresh rice seedlings under the following conditions: $27 \pm 1{ }^{\circ} \mathrm{C}$ with a light:dark (L:D) photoperiod of 14:10 h. To acquire the experimental insect samples, we 
randomly collected the $N$. lugens nymphs and then treated them with the fungal M. anisopliae CQMa421. The preparation of a suspension of $1 \times 10^{8}$ conidia/mL of M. anisopliae was performed as described in our previous study [21].

For individual insect treatment, we first transferred 10 fresh rice seedlings to a column bucket with a diameter of $10 \mathrm{~mm}$ and a height of $150 \mathrm{~mm}$. Then, nymphs of $N$. lugens were inoculated on the rice plants and sprayed with the prepared M. anisopliae suspension. After this treatment, the $N$. lugens nymphs were incubated in a bioassay room under a $27 \pm 1{ }^{\circ} \mathrm{C}$ and 14:10 $\mathrm{h}(\mathrm{L}: \mathrm{D})$ photoperiod. The control-group individuals were treated with distilled water using the same method indicated above. Finally, N. lugens nymphs from both the M. anisopliae-treated and control groups were collected after incubation on the rice seedings for $4 \mathrm{~h}, 8 \mathrm{~h}, 16 \mathrm{~h}$, or $24 \mathrm{~h}$. Three replicates were performed for each group, and a total of twenty-four sample groups of $N$. lugens individuals were flash frozen in liquid nitrogen and stored prior to RNA extraction.

\subsection{Small RNA (sRNA) Extraction and Sequencing}

The whole bodies of $N$. lugens nymphs from the M. anisopliae-infected or noninfected groups were collected at $4 \mathrm{~h}, 8 \mathrm{~h}, 16 \mathrm{~h}$, and $24 \mathrm{~h}$ posttreatment for sRNA sequencing. The total RNA of N. lugens nymphs was extracted using TRIzol reagent (Invitrogen, Carlsbad, CA, USA) according to the manufacturer's instructions. The purity, concentration, and integrity of the RNA samples were tested using a NanoPhotometer ${ }^{\circledR}$ spectrophotometer (IMPLEN, Westlake Village, CA, USA). The samples were evaluated in agarose gels to ensure that they showed a sufficiently high quality for transcriptome sequencing. The preparation of the sRNA sequencing library was performed as follows: first, the $3^{\prime}$ SR and $5^{\prime}$ SR adaptors were ligated to the ends of the sRNAs by using the T4 RNA ligase. Then, firststrand cDNA was synthesized by reverse transcription. PCR amplification was performed, and size selection was carried out via polyacrylamide gel electrophoresis (PAGE). The PAGE was used for fragment screening purposes, with rubber cutting recycling of the pieces to produce small RNA libraries. The PCR products were purified (AMPure XP system), and library quality was assessed. The clustering of the index-coded samples was performed on a cBot Cluster Generation System using the TruSeq PE Cluster Kit v4-cBotHS (Illumina, San Diego, CA, USA) according to the manufacturer's instructions. After cluster generation, the library preparations were sequenced on an Illumina platform, and single-end reads were generated by a service provider (BioMarker Technologies, Beijing, China). The Illumina sequence reads of N. lugens were deposited in the NCBI SRA database (accession no. PRJNA686491).

\subsection{N. lugens miRNA Prediction}

The raw reads in FASTQ format were first processed with in-house Perl scripts. In this step, clean reads were obtained by removing reads containing adapters, reads containing ploy-N sequences and low-quality reads for the raw data. In this treatment, all reads were trimmed and cleaned by removing sequences smaller than $18 \mathrm{nt}$ or longer than 30 nt. Additionally, the Q20 and Q30 values, GC contents, and sequence duplication levels were calculated from the clean data. All downstream analyses were based on the clean data with high quality. Clean reads were obtained using Bowtie tools software via sequence alignment against the Silva database, GtRNAdb database, Rfam database, and Repbase database, and ribosomal RNAs (rRNAs), transfer RNAs (tRNAs), small nuclear RNAs (snRNAs), small nucleolar RNAs (snoRNAs), and other types of noncoding RNAs (ncRNAs) and repeats were filtered to identify and predict miRNAs. The remaining reads were used to identify known miRNAs and novel miRNAs by mapping with the N. lugens genome (NCBI project accession: PRJNA177647) [42] using the Bowtie program [43].

\subsection{Differential Expression Analysis and Functional Annotation}

For the differential expression analysis of the M. anisopliae-infected or noninfected $N$. lugens groups, we used the DESeq2 R package. DESeq2 provides statistical routines 
for determining differential expression from digital miRNA expression data by using a model based on the negative binomial distribution. The resulting $\mathrm{P}$ values were adjusted using the Benjamini and Hochberg approach for controlling the false discovery rate. All of the miRNAs with a $\left|\log _{2}(\mathrm{FC})\right| \geq 1.5$ and $p \leq 0.05$ predicted by DESeq 2 were assigned as differentially expressed miRNAs (DEmiRNAs).

Prediction of the potential target genes of differentially expressed miRNAs was conducted using the miRanda and RNAhybrid software packages [44,45]. Gene functional annotation of $N$. lugens was based on the following databases: $\mathrm{Nr}$ (NCBI non-redundant protein sequences); Nr (NCBI non-redundant nucleotide sequences); Pfam (Protein family); Swiss-Prot (A manually annotated and reviewed protein sequence database); KO (KEGG Orthologue database); and GO (Gene Ontology). The expression of miRNAs in all libraries was normalized based on the TPM algorithm, and the formula was as follows:

$$
\mathrm{TPM}=\text { Readcount } \times 10^{6} / \text { MappedReads }
$$

The genome database of N. lugens (Nilaparvata lugens NilLug1.0) used as the background to determine GO and KEGG terms enriched within the predicted targets dataset. Gene Ontology (GO) (http: / / www.geneontology.org/, accessed on 22 November 2019) enrichment analysis of the DEmiRNAs was implemented by using the GOseq R packagebased Wallenius noncentral hypergeometric distribution to identify the significantly enriched terms [46]. Kyoto Encyclopedia of Genes and Genomes (KEGG) pathway enrichment analysis was conducted to predict and identify the significant pathways, with datasets generated by genome sequencing or other high-throughput experimental technologies (http: / / www.genome.jp/kegg/, accessed on 22 November 2019). KO-based Annotation System (KOBAS) is an open-access system to use $\mathrm{KO}$ as a controlled vocabulary to automatically annotate a set of sequences, which can identify the most frequent and the most significantly enriched pathways in a given set of sequences [47]. We used it to test the statistical enrichment of differential expression genes in KEGG pathways.

\subsection{Validation by $R T-q P C R$}

We used real-time quantitative PCR (RT-qPCR) to analyze the expression of genes and to confirm the results of RNA sequencing. The highly expressed $10 \mathrm{miRNAs}$ among the DEmiRNAs were randomly selected. The RT-qPCR was performed on a Bio-Rad iQ2 optical system (Bio-Rad, Hercules, CA, USA) with a QuantiNove SYBR Green PCR Kit (QIAGEN, Dusseldorf, Germany) following the instructions of the manufacturer. The $\beta$-actin was used as an internal control. Each experiment was repeated in triplicate. Finally, data analysis was performed using the $2^{-\Delta \Delta C t}$ method. The primers designed for RT-qPCR in this study are listed in Table S1.

\section{Results}

\subsection{Overall and Size Distribution of N. lugens Total miRNAs}

To identify the $N$. lugens miRNAs, we constructed 24 libraries after challenge with $M$. anisopliae for $4 \mathrm{~h}, 8 \mathrm{~h}, 16 \mathrm{~h}$, and $24 \mathrm{~h}$ challenge by next-generation sequencing. The libraries generated for the control group and the $M$. anisopliae-infected group at different times were designated T-4 h vs. W-4 h, T-8 h vs. W-8 h, T-16 h vs. W-16 h, and T-24 h vs. W-24 h, respectively. In this analysis, a total of $541.47 \mathrm{M}$ raw reads were generated, and $478.62 \mathrm{M}$ clean reads were retained after removing the low-quality reads. The Q30 of all samples was greater than $94.19 \%$, indicating good sequencing data quality without low-quality sequences (Table S2). The mapped reads of all samples, except for T8-1 (59.08\%) and W4-3 $(59.18 \%)$, were more than $60 \%$ (Table S3).

We noted that the peak of the total miRNA read length distribution occurred at $22 \mathrm{nt}$, representing the typical lengths of conserved miRNAs; and next most abundant lengths were $25 \mathrm{nt}$, corresponding to piRNA-like sequences (Figure 1A). Additionally, the examination of the first nucleotide bias of the miRNAs showed a strong preference for uracil " $U$ " and adenine " $\mathrm{A}$ " (Figure $1 \mathrm{~B}$ ). The $5^{\prime}$ terminus of miRNA residues from 2 to 8 is 
believed to recognize the target mRNAs and repress posttranscription. The most abundant bases in such residues were $U, U, U, A, U, U$, and guanine " $G$ ", respectively (Figure 1B).

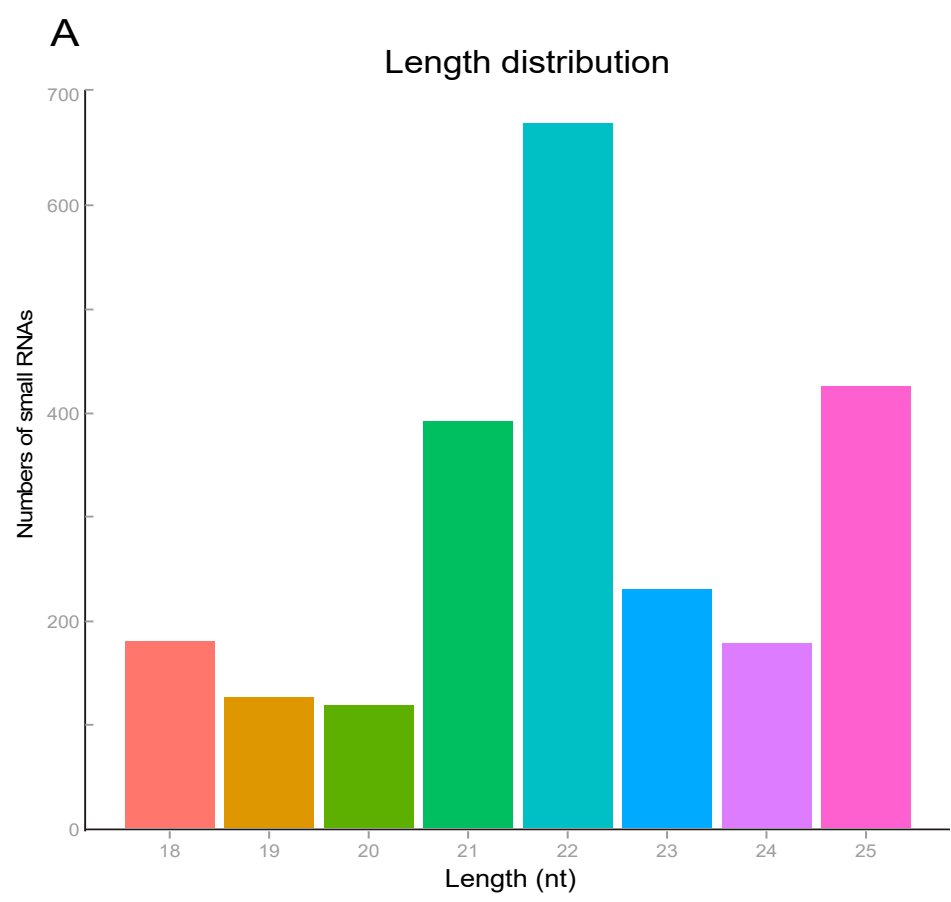

B

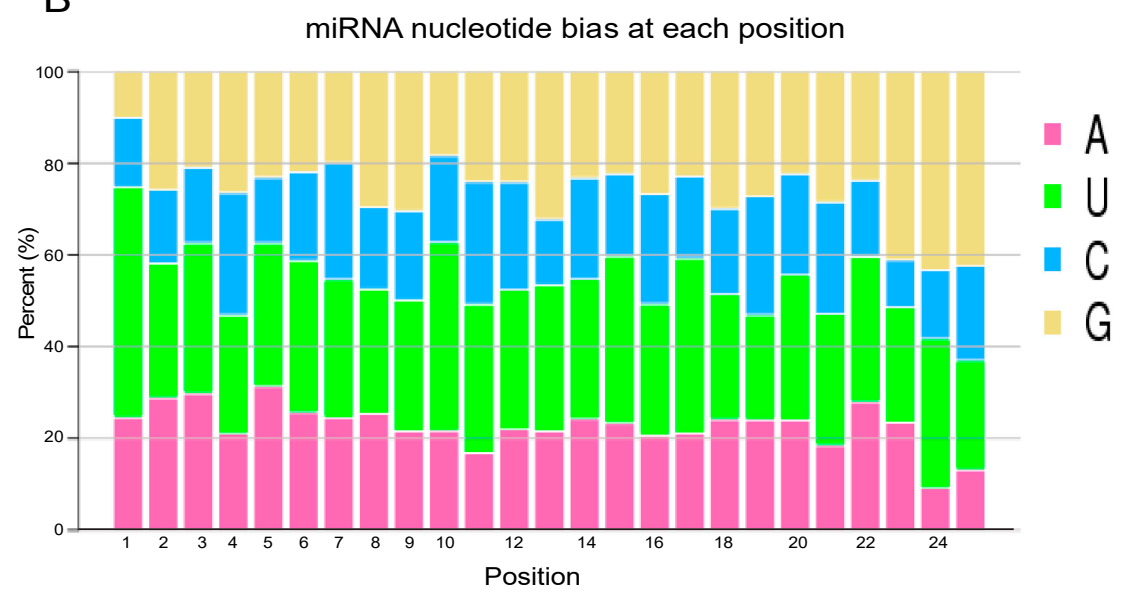

Figure 1. The length distribution and nucleotide bias of unique small RNA reads in the libraries of N. lugens. (A) The total length distribution of N. lugens small RNAs in the twenty-four libraries (4h, $8 \mathrm{~h}, 16 \mathrm{~h}$, and $24 \mathrm{~h}$ ) generated after M. anisopliae infection; (B) the first nucleotide bias at each position among miRNAs of different lengths in the twenty-four libraries.

\subsection{DEmiRNA Analysis of N. lugens after Fungal Treatment}

To identify N. lugens DEmiRNAs after M. anisopliae challenge, we calculated the read counts for each of the miRNAs and compared their expression levels during the timecourse of infection using DESeq2 according to the criteria of a $p$ value $<0.05$ and FC $>1.5$. After filtration, a total of 355 DEmiRNAs were identified between all libraries from the infected and uninfected groups with the $24 \mathrm{~h}$ experiments. Specifically, 58 DEmiRNAs were identified after $4 \mathrm{~h}$ of infection, including 32 upregulated and 26 downregulated miRNAs (Figure 2A). After $8 \mathrm{~h}$ of fungal infection, 62 DEmiRNAs were identified, including 30 upregulated vs. 32 downregulated miRNAs (Figure 2B). We identified 126 DEmiRNAs at $16 \mathrm{~h}$, including 71 upregulated and 55 downregulated miRNAs (Figure 2C). Finally, 109 DEmiRNAs were identified after $24 \mathrm{~h}$ of infection, including 40 upregulated and 
69 downregulated miRNAs (Figure 2D). Only 1 DEmiRNA was identified in all four timecourse treatment groups. Moreover, we found that the number of DEmiRNAs was variable at different times, showing an increasing tendency over time after fungal infection. The top ten N. lugens DEmiRNAs (up- or downregulated) after M. anisopliae infection also showed significant differences over the time course (Table S4).

A



C

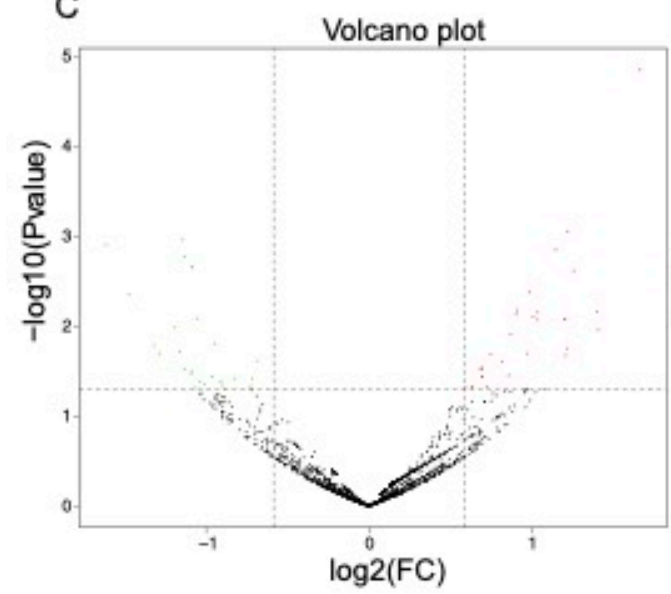

B

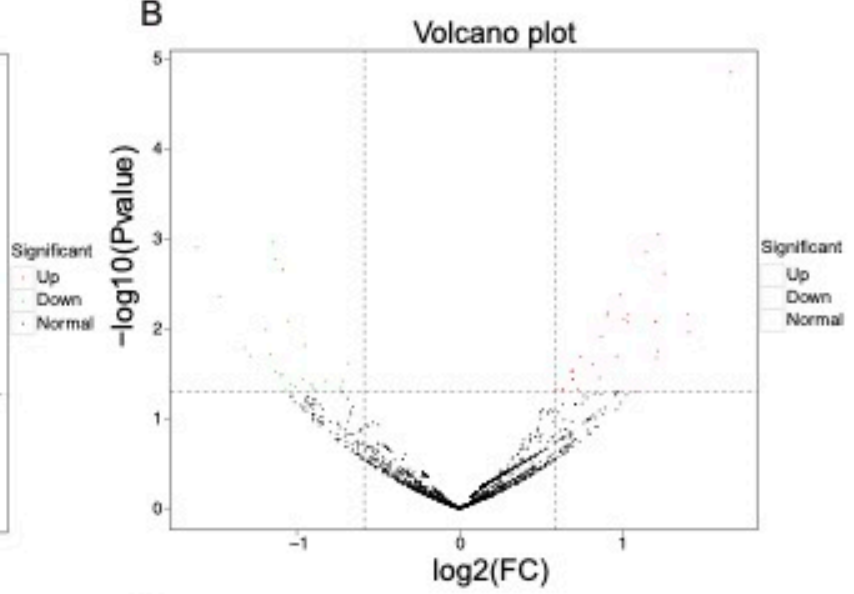

D

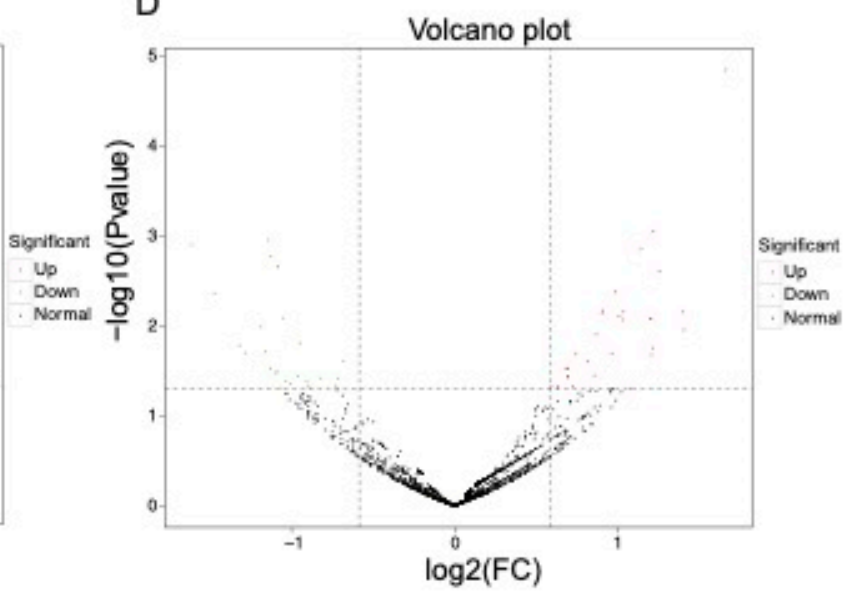

$\mathrm{E}$

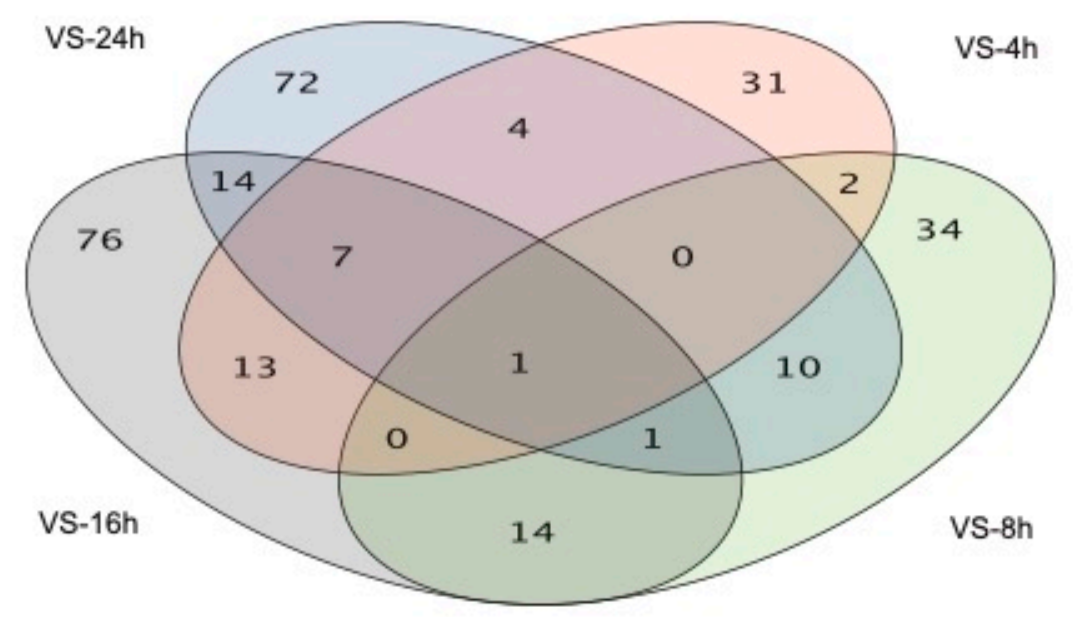

Figure 2. The volcano plot and numbers of differentially expressed miRNAs (DEmiRNAs) identified after M. anisopliae infection. (A) The volcano plot of DEmiRNAs at $4 \mathrm{~h}$ post-challenge; (B) the volcano plot of DEmiRNAs at $8 \mathrm{~h}$ post challenge; (C) the volcano plot of DEmiRNAs at $16 \mathrm{~h}$ post-challenge; (D) the volcano plot of DEmiRNAs at $24 \mathrm{~h}$ post-challenge; and (E) the Venn diagram of DEmiRNAs after M. anisopliae infection at 4, 8, 16, and $24 \mathrm{~h}$. 


\subsection{Functional Analysis of DEmiRNAs in N. lugens}

To further examine the functions of all DEmiRNAs in N. lugens, we predicted the target genes of the miRNAs in the GO databases and mapped them to different functions (Table S5). The annotated GO terms of the 4360 target mRNAs for the total DEmiRNAs predicated using RNAhybrid and miRanda algorithms were divided into the biological process, cell component, and molecular function categories. The differences in the abundances and numbers of the mRNAs associated with the four examined infection periods are shown according to the different GO categories of the 1036, 814, 1867, and 2171 target mRNAs identified after $4 \mathrm{~h}, 8 \mathrm{~h}, 16 \mathrm{~h}$, and $24 \mathrm{~h}$ of infection, respectively. In the biological process category, the target genes of miRNAs were majorly associated with the in cellular process and metabolic process functions. Membrane and cell components were the most enriched cellular component categories, while binding and catalytic activity were the most enriched molecular functions. Interestingly, there were no target mRNAs associated with detoxification functions identified at $4 \mathrm{~h}$ (Figure $3 \mathrm{~A}$ ), while this functional category showed enrichment at $8 \mathrm{~h}, 16 \mathrm{~h}$, and $24 \mathrm{~h}$ after infection (Figure 3B-D). Additionally, no target mRNAs were associated with the functions of antioxidant activity and electron carrier activity after $4 \mathrm{~h}$ of infection, but these two metabolic activity categories showed enrichment at $8 \mathrm{~h}$ and $16 \mathrm{~h}$ post-infection (Figure $3 \mathrm{~B}, \mathrm{C}$ ).

We further used KEGG to identify the metabolic and signal transduction pathways associated with the targets of the DEmiRNAs after M. anisopliae infection (Table S6). The target genes of 323 differentially expressed mRNAs identified after $4 \mathrm{~h}$ infection were mapped to 77 pathways in the KEGG database, including the FoxO signaling pathway, notch signaling pathway, steroid biosynthesis, etc. (Figure 4A). When $N$. lugens was challenged by $M$. anisopliae for $8 \mathrm{~h}, 82$ pathways (including lysine degradation, ubiquitin mediated proteolysis, mTOR signaling pathway, etc.) were found to be enriched with the targeted genes of 376 differentially expressed mRNAs (Figure 4B). A total of 2166 targets of 579 differentially expressed mRNAs identified after $16 \mathrm{~h}$ infection was mapped to 93 pathways in the KEGG database (including the ubiquitin-mediated pathway, phototransduction, mRNA surveillance pathway, etc.) (Figure 4C). We found that there were 2085 genes targeted including 435 differentially expressed mRNAs identified after $24 \mathrm{~h}$ infection mapped to 89 pathways, including the MAPK signaling pathway, starch and sucrose metabolism, endocytosis, etc. (Figure 4D). The top KEGG targets of the DEmiRNAs are shown in Figure 4 and mainly included the lysine degradation (KO: 00310), ubiquitin-mediated proteolysis (KO: 04120), starch and sucrose metabolism (KO: 00500), RNA transport (KO: 03013) and FoxO signaling (KO: 04068) pathways.

From the highly expressed DEmiRNAs, the Nr annotation of the target DEGs included the serine/threonine-protein kinase mTOR (NL-miR-2333), serine/threonine-protein kinase PAK 3, insulin receptor, and E3 ubiquitin-protein ligase UBR2 (NL-miR-1047); thioredoxin domain-containing protein (NL-miR-156); and E3 ubiquitin-protein ligase MYCBP2 (NL$\mathrm{miR}-488$ ) at $4 \mathrm{~h}$ infection. Eight hours after $M$. anisopliae infection, the target DEGs mainly included the apoptosis-resistant E3 ubiquitin protein ligase 1, nucleoprotein TPR, diacylglycerol kinase theta isoform X3, and protein phosphatase PHLPP (NL-miR-260); cytosolic carboxypeptidase (NL-miR-1675); transient receptor potential channel pyrexia (NL-miR2180); phospholipid phosphatase and zinc finger protein (NL-miR-707); glucose transporter (NL-miR-1385); and DNA topoisomerase (NL-miR-1547). The DEGs at $16 \mathrm{~h}$ included a serine/threonine-protein kinase, histone acetyltransferase, E3 ubiquitin-protein ligase, and extracellular sulfatase corresponding to NL-miR-1982; putative mediator of RNA polymerase II, GTPase-activating protein, phenoloxidase, and odorant receptor corresponding to NL-miR-1147; phospholipid-transporting ATPase corresponding to NL-miR-453; and serine/threonine-protein kinase and GTPase-activating protein corresponding to NLmiR-1462. We noted that the DEGs at $24 \mathrm{~h}$ included the heparin sulfate glucosamine, tRNA modification GTPase, histone-lysine N-methyltransferase, and glucose-6-phosphate 1-dehydrogenase (NL-miR-54); transcriptional regulator and histone acetyltransferase 
(NL-miR-1546); and activating signal co-integrator, tripeptidyl-peptidase, and pyruvate carboxylase (NL-miR-756) (Table S7).

A

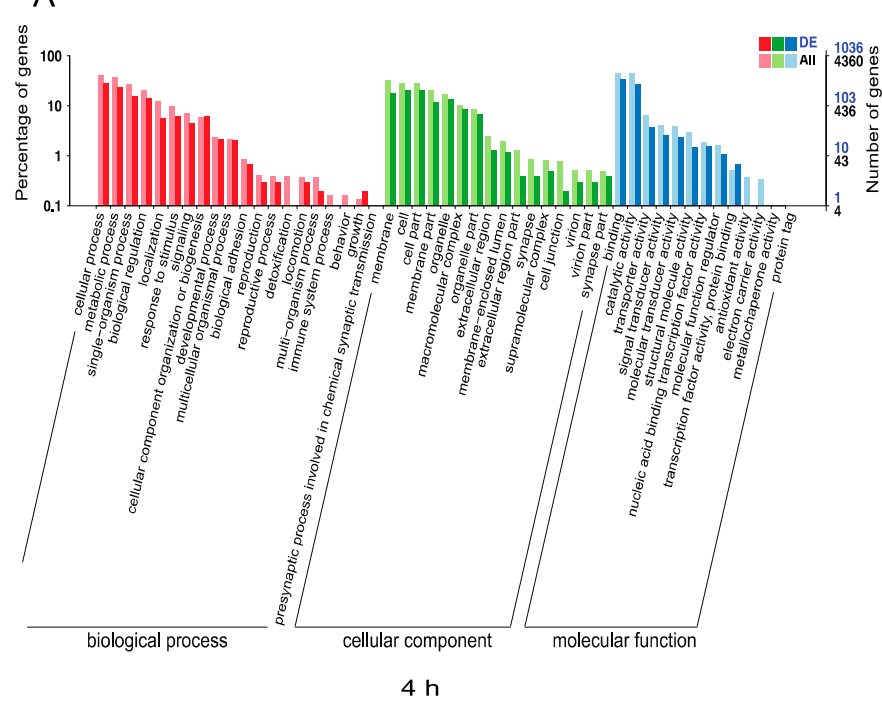

C

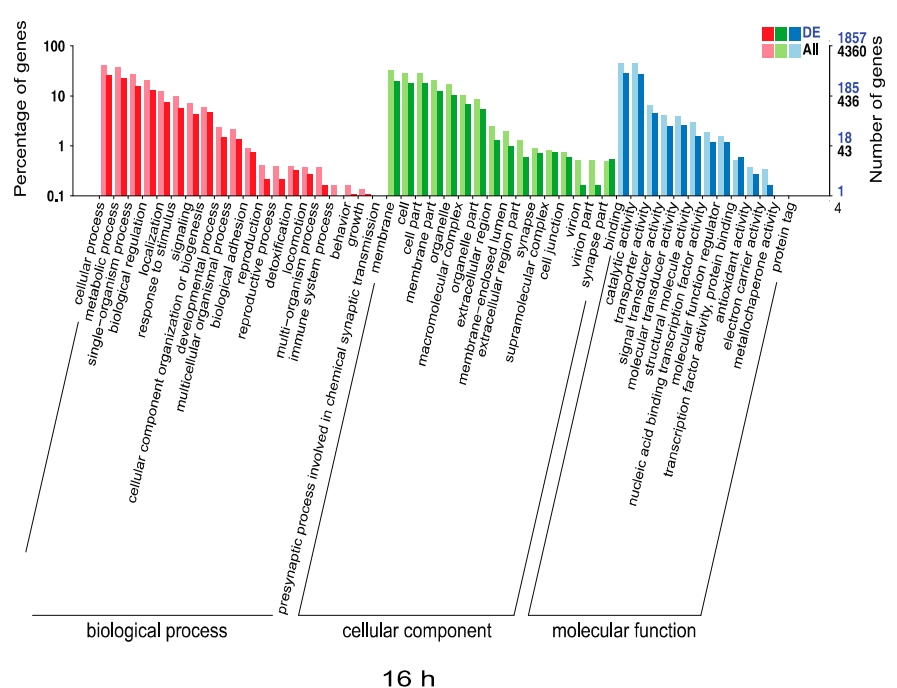

B

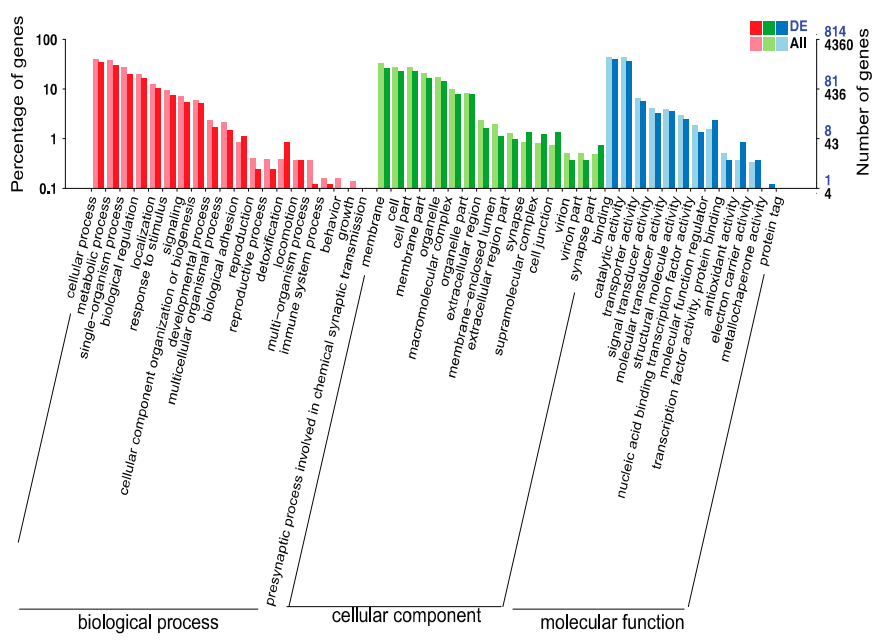

$8 \mathrm{~h}$

D

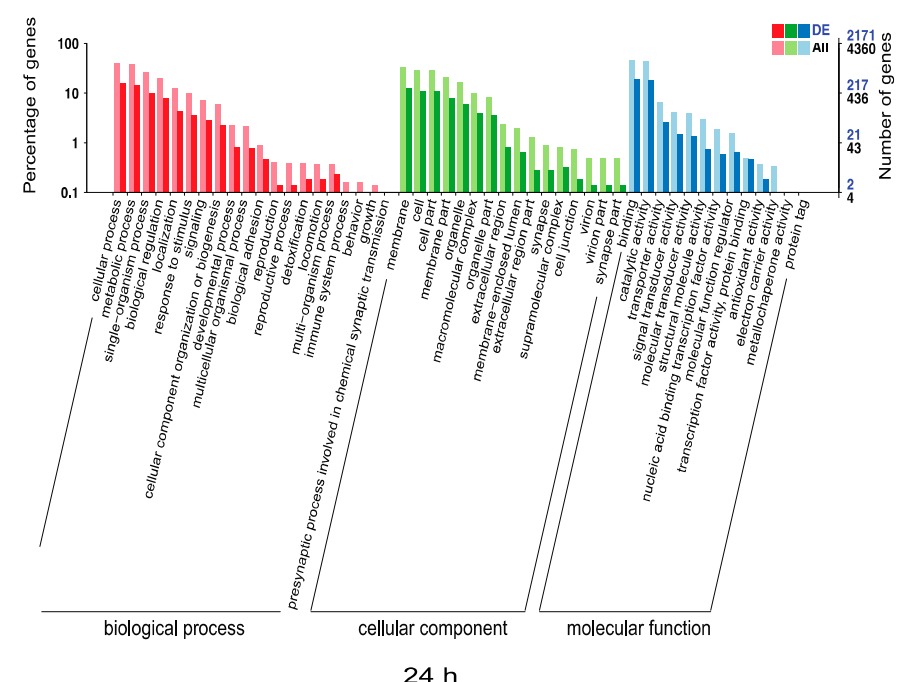

Figure 3. The GO categories of $N$. lugens DEmiRNAs identified during M. anisopliae infection. (A) The GO categories of $N$. lugens DEmiRNAs at $4 \mathrm{~h}$ post $M$. anisopliae infection; (B) the GO categories of $N$. lugens DEmiRNAs at $8 \mathrm{~h}$ post $M$. anisopliae infection; (C) the GO categories of N. lugens DEmiRNAs at $16 \mathrm{~h}$ post M. anisopliae infection, and (D) the GO categories of $N$. lugens DEmiRNAs at $24 \mathrm{~h}$ post $M$. anisopliae infection.

\subsection{Validation of DEmiRNAs by RT-qPCR}

To further validate the DEmiRNAs identified through sequencing, we used RT-qPCR to analyze gene expression and confirm the results of RNA sequencing. We selected 10 of the highly expressed miRNAs based on the Illumina sequencing results. The results showed that the expression trends of the selected miRNAs showed a slight discrepancy from the findings of the sequencing analysis (Figure 5), which might be due to the differences in the sensitivity, specificity, and applied algorithms between the two techniques. 
A

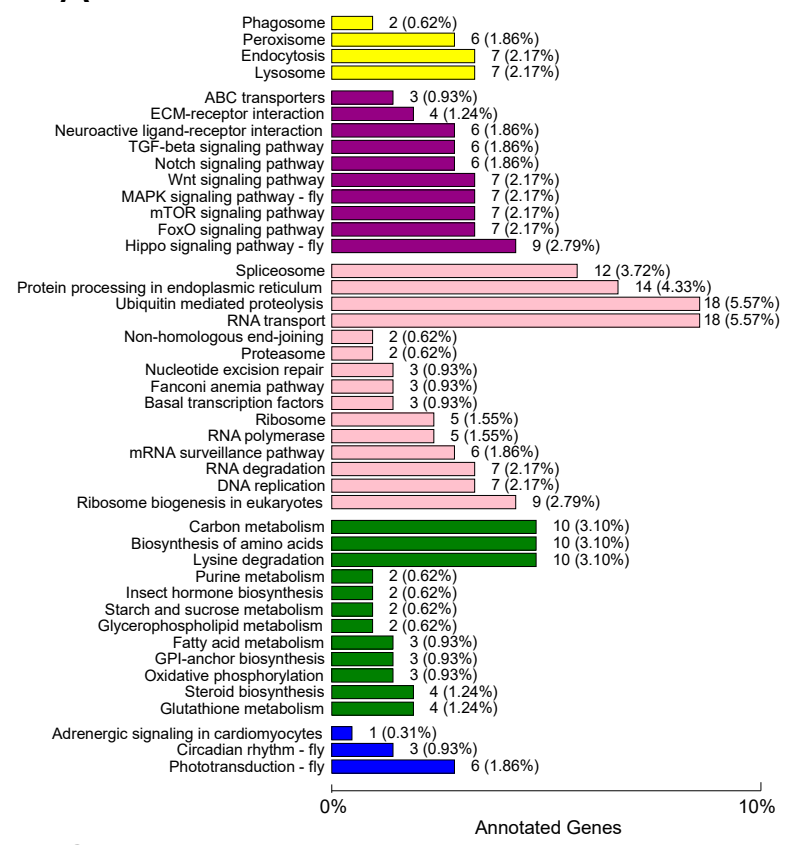

C

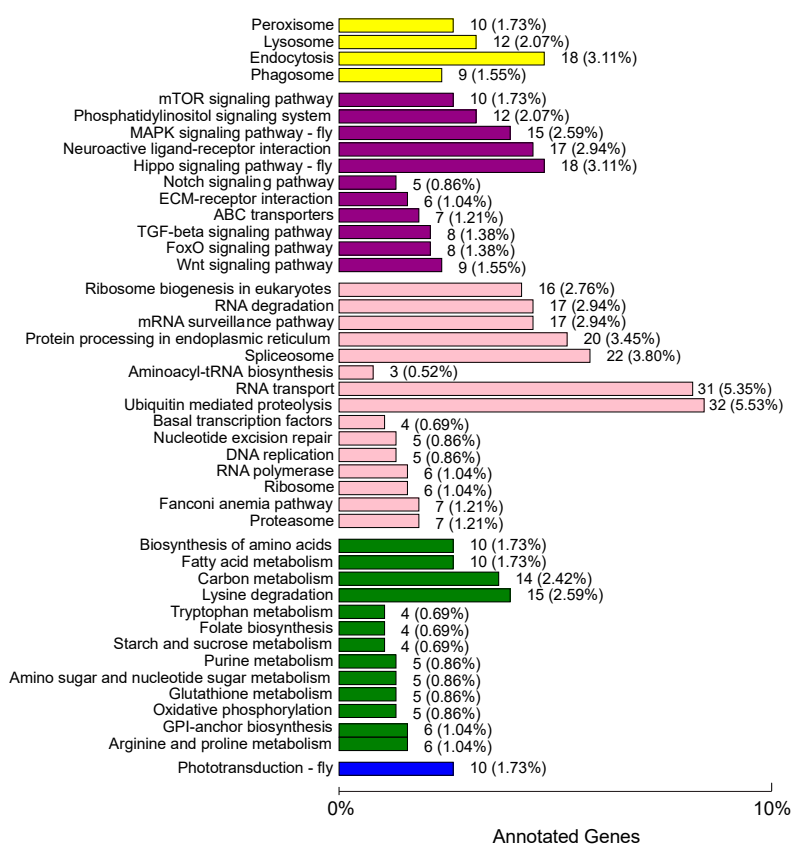

B

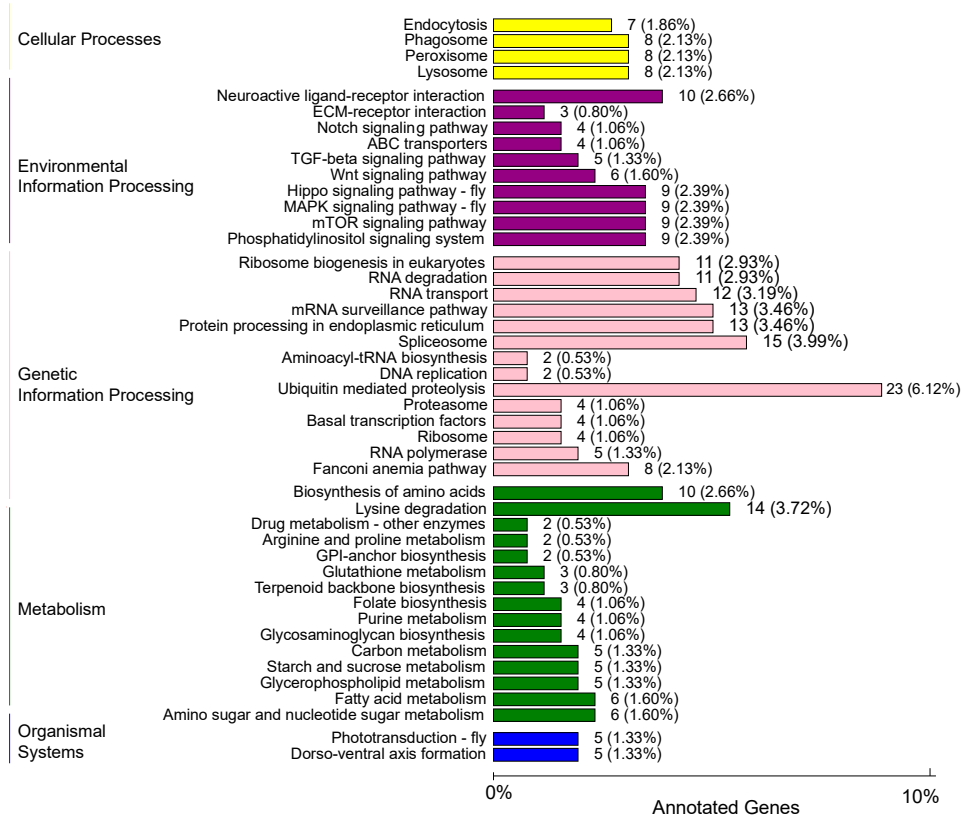

D

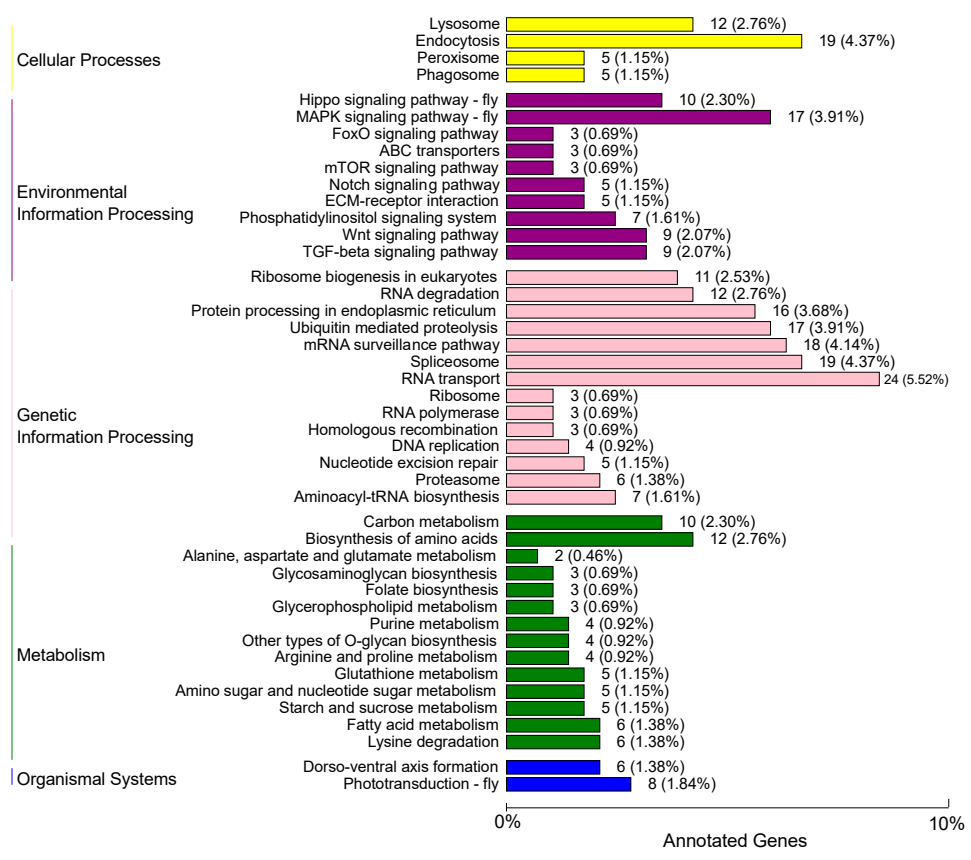

Figure 4. The enrichment and dispersion of differentially expressed miRNAs in KEGG pathways after M. anisopliae infection. (A) The identified pathways of DEmiRNAs after $4 \mathrm{~h}$ of $M$. anisopliae infection; (B) the identified pathways of DEmiRNAs after $8 \mathrm{~h}$ of M. anisopliae infection; (C) the identified pathways of DEmiRNAs after $16 \mathrm{~h}$ of $M$. anisopliae infection; and (D) the identified pathways of DEmiRNAs after $24 \mathrm{~h}$ of M. anisopliae infection. The asterisks indicate significant differences according to a $p$ value $<0.05$. 


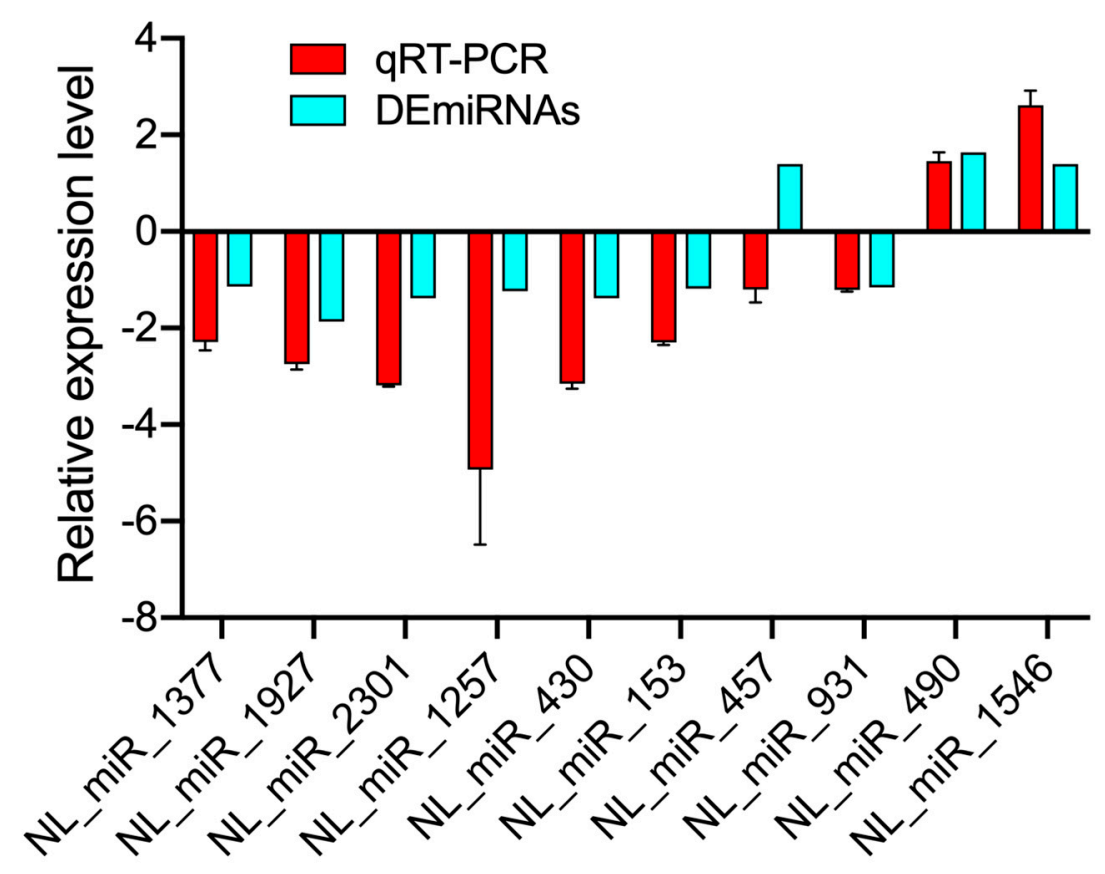

Figure 5. The validation of RNA sequencing and RT-qPCR results for target genes. Three replicates were performed for each miRNA, and error bars represent the mean $\pm \mathrm{SE}$.

\section{Discussion}

The field population of the pest $N$. lugens has evolved high resistance (more than 1000-fold) to many common chemical insecticides, such as imidacloprid and buprofezin [48]. The use of chemicals imposes significant negative effects on species diversity and the wellbeing of ecosystems $[5,49]$. Alternative control tools, such as entomopathogenic fungi, present good potential for the insect pest control under both greenhouse and large-scale field conditions $[23,50]$. The entomopathogenic fungus $M$. anisopliae has been used for the control of several insect pests, including the major rice pests. In our previous study, we isolated the fungal $M$. anisopliae strain CQMa421 to challenge $N$. lugens nymphs and adults, which resulted in high mortality. Additionally, this fungus has been suggested for use in long-term control under field conditions and has relatively limited effects on nontargets species (i.e., microbial diversity and structure) [22]. Although a few studies focused on the transcriptomic level of $N$. lugens under stressful conditions, less attention has been paid to the analysis of this fungus at the posttranscriptional level, especially under entomopathogenic fungal challenge. In this study, we compared the miRNAs of N. lugens after challenge with the entomopathogenic fungus M. anisopliae in different infection stages. This investigation at the posttranscriptional level will provide important insights for further study of the interactions between the entomopathogenic fungus and the insect host. These results may also contribute to the development of new strategies (i.e., new targets for RNAi) for the control of this pest.

$N$. lugens miRNAs were identified after the fungal M. anisopliae infection for $4 \mathrm{~h}$ to $24 \mathrm{~h}$, and the results showed variation in terms of both the numbers and targets of the identified miRNAs. The targets of the miRNAs identified after $M$. anisopliae infection are involved in the many metabolic processes and pathways, including carbon metabolism, starch and sucrose metabolism, ubiquitin-mediated proteolysis, the FoxO signaling pathway, and the pentose phosphate pathway. To defend against pathogens, insect hosts have evolved complex mechanisms for responding to and eliminating pathogen infection [51]. The cuticle is a protective barrier that helps to recognize and defend against pathogenic infection [52]. When pathogens adhere to the insect cuticle, the pattern recognition molecules (i.e., peptidoglycan recognition proteins, $\beta$-1,3-glucan recognition proteins, scavenger receptors, and galectins) of the insect host are activated [53,54]. Moreover, the innate immune system, 
including cellular and humoral immune responses, of insect hosts plays important roles in defending against pathogens, although insects lack an adaptive immune response $[55,56]$.

We found that a few miRNAs were specifically expressed under $M$. anisopliae infection at different times during initial post-infection, indicating that these miRNAs play vital roles in defending $N$. lugens against the entomopathogenic fungus $M$. anisopliae. Conidial adhesion, detoxification, and penetration of entomopathogenic fungi on the cuticle of insect hosts are important processes in initial infection [52]. During this period, certain proteins (MAD1, G-protein-coupled receptors (GPCRs), dehydrogenases, and lipases) and pathways (mitogen-activated protein kinase (MAPK) and protein kinase A (PKA) pathways) are involved in in these processes [57]. Other studies have shown that fungal infection may result in the expression of specific genes with different time courses [51]. Additionally, the number and type of hemocytes, which play key roles in cellular immunity, have been shown to vary with post-infection time [58], while our study did not check these changes.

In our study, there was no apparent immune response at $4 \mathrm{~h}$ post- $M$. anisopliae infection (Figure $3 \mathrm{~A}$ ), but we noted an immune response at $8 \mathrm{~h}$ post-infection. Furthermore, the targets of the detoxification process were first identified at $8 \mathrm{~h}$ post-infection and showed a high expression. After $8 \mathrm{~h}$ of fungal infection, miRNA targets with catalytic activity showed high expression, while chemical synaptic transmission was significantly inhibited at this time. We also noted that DEmiRNAs were slightly more abundant at $16 \mathrm{~h}$ than at $24 \mathrm{~h}$, and the target genes and pathways identified at these time points were different (Tables S4 and S7). While miR-197 showed high expression at $16 \mathrm{~h}$, miR-277 and miR-237 exhibited low expression. In contrast, miR-1834 showed high expression at $24 \mathrm{~h}$, when miR165 showed low expression. According to these target mRNAs, an RNAi-based technology can be developed and further combined with fungal agents for the control of insect pests. In fact, a previous study has been conducted to evaluate their combined use for rice pest control, suggesting a good potential for this pest control [20].

The most common metabolic processes and pathways identified within the initial $24 \mathrm{~h}$ after M. anisopliae infection were recognition, energy metabolism, the FoxO signaling pathway, and the MAPK signaling pathway, indicating these physiological responses in $N$. lugens are intense during fungal infection. These pathways are important for regulating organismal development, immune responses, and behavior [59,60]. In this study, 58 of the DEmiRNAs at $4 \mathrm{~h}$ targeted DNA replication, lysine degradation, ubiquitin-mediated proteolysis, and RNA transport. After $8 \mathrm{~h}$, the top pathways of the targets were related to lysine degradation, ubiquitin-mediated proteolysis, starch and sucrose metabolism, and the mRNA surveillance pathway. We noted that there were specific pathways identified at $16 \mathrm{~h}$ (i.e., the Hippo signaling pathway) and $24 \mathrm{~h}$ (i.e., the MAPK signaling pathway) after $M$. anisopliae infection. The identified DEmiRNAs and targeting pathways exhibited differences in abundance during M. anisopliae infection from 4 to $24 \mathrm{~h}$. In fact, several studies have shown that different developmental stages and sexes also exhibit miRNA differences [30,32]. The temporal patterns between host and fungus have also been studied in the insect Plutella xylostella, and the results showed time-dependent expression [61]. Furthermore, we noted that the qPCR result showed a slight discrepancy from the sequencing results, and we believe that a time-point selection of miRNAs for qPCR would better reflect the sequencing results.

In conclusion, we identified and analyzed the posttranscriptional regulation of miRNAs after M. anisopliae infection. A total of 2324 miRNAs, including 355 DEmiRNAs, were identified and found to target 11,076 genes (Table S5). Our results revealed the interactions between the $N$. lugens host and the infecting entomopathogenic fungus M. anisopliae and provide important insights for further research into the role of N. lugens miRNAs in responding to fungal infection. They may also contribute to the development of control strategies for this pest. 
Supplementary Materials: The following are available online at https:/ / www.mdpi.com/article/10 .3390/jof7040295/s1, Table S1: Primers used for RT-qPCR in this study, Table S2: Statistical summary of $N$. lugens miRNAs identified in the M. anisopliae-infected and noninfected groups. Table S3: The information of mapped reads of all samples after M. anisopliae treatment or control group. Table S4: Top ten up- and down-regulated DEmiRNAs in N. lugens after M. anisopliae challenge. Table S5: The number information of annotated targets of miRNAs with different database. Table S6: The identification of pathways, target genes of N. lugens miRNAs after fungal infection during different times. Table S7: Predicted targets of highly expressed DEmiRNAs in N. lugens.

Author Contributions: Conceptualization, J.X. and Y.X.; methodology, Y.P. and J.X.; project administration, J.X. and Y.X.; investigation, Y.P. and J.X.; writing-review and editing, J.X., Y.X., and Y.P.; funding acquisition, J.X. All authors have read and agreed to the published version of the manuscript.

Funding: This work was supported by the grants from the National Natural Science Foundation of China (Project No. 31801798), the Group of Chongqing Talent Plan (Project No. CQYC202003216), and the Fundamental Research Funds for the Central Universities (Chongqing University) with Project No. 2020CDJQY-A020.

Institutional Review Board Statement: Not applicable.

Informed Consent Statement: Not applicable.

Data Availability Statement: All sequence data are available in the NCBI GenBank following the accession numbers (PRJNA686491) in the manuscript.

Acknowledgments: We thank Na Yu for providing the original insect species and Chunfang Huang for assistance with rearing the insects used in this experiment.

Conflicts of Interest: The authors declare no conflict of interest.

\section{References}

1. Lou, Y.G.; Zhang, G.R.; Zhang, W.Q.; Hu, Y.; Zhang, J. Biological control of rice insect pests in China. Biol. Control. 2013, 67, 8-20. [CrossRef]

2. Cheng, J. Rice planthopper problems and relevant causes in China. Rice 2009, 1, 1-32.

3. Wang, Y.; Tang, M.; Hao, P.; Yang, Z.; Zhu, L.; He, G. Penetration into rice tissues by brown planthopper and fine structure of the salivary sheaths. Entomol. Exp. Appl. 2010, 129, 295-307. [CrossRef]

4. Hibino, H. Biology and epidemiology of rice viruses. Annu. Rev. Phytopathol. 1996, 34, 249-274. [CrossRef]

5. Desneux, N.; Decourtye, A.; Delpuech, J.M. The sublethal effects of pesticides on beneficial arthropods. Annu. Rev. Entomol. 2007, 52, 81-106. [CrossRef] [PubMed]

6. Ko, K.; Liu, Y.; Hou, M.; Babendreier, D.; Zhang, F.; Song, K. Toxicity of insecticides targeting rice planthoppers to adult and immature stages of Trichogramma chilonis (Hymenoptera: Trichogrammatidae). J. Econ. Entomol. 2015, 108, 69-76. [CrossRef] [PubMed]

7. Wu, S.F.; Zeng, B.; Zheng, C.; Mu, X.C.; Zhang, Y.; Hu, J.; Zhang, S.; Gao, C.F.; Shen, J.L. The evolution of insecticide resistance in the brown planthopper (Nilaparvata lugens Stål) of China in the period 2012-2016. Sci. Rep. 2018, 8, 4586. [CrossRef] [PubMed]

8. Huang, J.; Hu, R.; Rozelle, S.; Pray, C. Insect-resistant GM rice in farmers' fields: Assessing productivity and health effects in China. Science 2005, 308, 688-690. [CrossRef]

9. Estruch, J.J.; Carozzi, N.B.; Desai, N.; Duck, N.B.; Warren, G.W.; Koziel, M.G. Transgenic plants: An emerging approach to pest control. Nat. Biotechnol. 1997, 15, 137-141. [CrossRef]

10. Price, D.R.; Gatehouse, J.A. RNAi-mediated crop protection against insects. Trends Biotechnol. 2008, 26, 393-400. [CrossRef] [PubMed]

11. Hamiduzzaman, M.M.; Sinia, A.; Guzman-Novoa, E.; Goodwin, P.H. Entomopathogenic fungi as potential biocontrol agents of the ecto-parasitic mite, Varroa destructor, and their effect on the immune response of honey bees (Apis mellifera L.). J. Invertebr. Pathol. 2012, 111, 237-243. [CrossRef]

12. Zimmermann, G. The entomopathogenic fungus Metarhizium anisopliae and its potential as a biocontrol agent. Pest Manag. Sci. 2010, 37, 375-379. [CrossRef]

13. Jiang, W.; Peng, Y.; Ye, J.; Wen, Y.; Liu, G.; Xie, J. Effects of the entomopathogenic fungus Metarhizium anisopliae on the mortality and immune response of Locusta migratoria. Insects 2019, 11, 36. [CrossRef] [PubMed]

14. Rice, S.J.; Baker, D.K.; Leemon, D.M. Development of mycoinsecticide formulations with Beauveria bassiana and Metarhizium anisopliae for the control of lesser mealworm, Alphitobius diaperinus, in chicken broiler houses. Biocontrol 2019, 64, 489-500. [CrossRef] 
15. Bordalo, M.D.; Gravato, C.; Beleza, S.; Campos, D.; Lopes, I.; Pestana, J.L.T. Lethal and sublethal toxicity assessment of Bacillus thuringiensis var. israelensis and Beauveria bassiana based bioinsecticides to the aquatic insect Chironomus riparius. Sci. Total Environ. 2020, 698, 134155. [CrossRef]

16. Fite, T.; Tefera, T.; Negeri, M.; Damte, T.; Sori, W. Evaluation of Beauveria bassiana, Metarhizium anisopliae, and Bacillus thuringiensis for the management of Helicoverpa armigera (Hubner) (Lepidoptera: Noctuidae) under laboratory and field conditions. Biocontrol Sci. Technol. 2019, 30, 278-295. [CrossRef]

17. Knols, B.G.; Bukhari, T.; Farenhorst, M. Entomopathogenic fungi as the next-generation control agents against malaria mosquitoes. Future Microbiol. 2010, 5, 339-341. [CrossRef] [PubMed]

18. Peng, G.; Xia, Y. Integration of an insecticidal scorpion toxin (Bj $\alpha \mathrm{IT})$ gene into Metarhizium acridum enhances fungal virulence towards Locusta migratoria manilensis. Pest Manag. Sci. 2015, 71, 58-64. [CrossRef]

19. Fan, Y.; Borovsky, D.; Hawkings, C.; Ortiz-Urquiza, A.; Keyhani, N.O. Exploiting host molecules to augment mycoinsecticide virulence. Nat. Biotechnol. 2012, 30, 35-37. [CrossRef]

20. Pan, C.Y.; Cai, Y.J.; Li, T.C.; Zhang, W.Q. Control effect of Metarhizium anisopliae and its mixture with dsRNA on the brown planthopper. J. Environ. Entomol. 2016, 38, 1071-1077.

21. Tang, J.F.; Liu, X.Y.; Ding, Y.C.; Jiang, W.J.; Xie, J.Q. Evaluation of Metarhizium anisopliae for rice planthopper control and its synergy with selected insecticides. Crop Prot. 2019, 121, 132-138. [CrossRef]

22. Peng, Y.; Tang, J.; Hong, M.; Xie, J. Suppression of rice planthopper populations by the entomopathogenic fungus Metarhizium anisopliae without affecting the rice microbiota. Appl. Environ. Microb. 2020, 86, 1-12. [CrossRef] [PubMed]

23. Peng, G.; Xie, J.; Guo, R.; Keyhani, N.O.; Zeng, D.; Yang, P.; Xia, Y. Long-term field evaluation and large-scale application of a Metarhizium anisopliae strain for controlling major rice pests. J. Pest Sci. 2021, 1-12. [CrossRef]

24. Ambros, V. microRNAs: Tiny regulators with great potential. Cell 2001, 107, 823-826. [CrossRef]

25. Ghildiyal, M.; Zamore, P.D. Small silencing RNAs: An expanding universe. Nat. Rev. Genet. 2009, 10, 94-108. [CrossRef] [PubMed]

26. Moss, E.G. MicroRNAs: Hidden in the Genome. Curr. Biol. 2002, 12, R138-R140. [CrossRef]

27. Lau, N.C.; Lim, L.P.; Weinstein, E.G.; Bartel, D.P. An abundant class of tiny RNAs with probable regulatory roles in Caenorhabditis elegans. Science 2001, 296, 858-862. [CrossRef]

28. Ambros, V.; Chen, X. The regulation of genes and genomes by small RNAs. Development 2007, 134, 1635-1641. [CrossRef]

29. Mukherjee, K.; Vilcinskas, A. Development and immunity-related microRNAs of the lepidopteran model host Galleria mellonella. BMC Genom. 2014, 15, 705. [CrossRef]

30. Zhang, Z.; Li, T.; Tang, G. Identification and characterization of conserved and novel miRNAs in different development stages of Atrijuglans hetaohei Yang (Lepidoptera: Gelechioidea). J. Asia-Pac. Entomol. 2018, 21, 9-18. [CrossRef]

31. Ylla, G.; Piulachs, M.-D.; Belles, X. Comparative analysis of miRNA expression during the development of insects of different metamorphosis modes and germ-band types. BMC Genom. 2017, 18, 774. [CrossRef] [PubMed]

32. Peng, W.; Tariq, K.; Xie, J.; Zhang, H. Identification and characterization of sex-biased MicroRNAs in Bactrocera dorsalis (Hendel). PLoS ONE 2016, 11, e0159591. [CrossRef]

33. Li, X.; Zhang, F.; Coates, B.; Zhang, Y.; Zhou, X.; Cheng, D. Comparative profiling of microRNAs in the winged and wingless English grain aphid, Sitobion avenae (F.) (Homoptera: Aphididae). Sci. Rep. 2016, 6, 35668. [CrossRef] [PubMed]

34. Xu, L.; Zhang, J.; Zhan, A.; Wang, Y.; Ma, X.; Jie, W.; Cao, Z.; Omar, M.A.A.; He, K.; Li, F. Identification and analysis of MicroRNAs associated with wing polyphenism in the brown planthopper, Nilaparvata lugens. Int. J. Mol. Sci. 2020, 21, 9754. [CrossRef] [PubMed]

35. Leung, A.K.L.; Sharp, P.A. MicroRNAfunctions in stress responses. Mol. Cell 2010, 40, 280-293. [CrossRef] [PubMed]

36. López-Galiano, M.J.; Sentandreu, V.; Martínez-Ramírez, A.C.; Rausell, C.; Real, M.D.; Camañes, G.; Ruiz-Rivero, O.; Crespo-Salvador, O.; García-Robles, I. Stress associated microRNAs in Solanum lycopersicum by high-throughput sequencing. Genes 2019, 10, 475. [CrossRef] [PubMed]

37. Shakeel, M.; Xu, X.; Xu, J.; Li, S.; Yu, J.; Zhou, X.; Xu, X.; Hu, Q.; Yu, X.; Jin, F. Genome-Wide identification of destruxin A-responsive immunity-related microRNAs in diamondback moth, Plutella xylostella. Front. Immunol. 2018, 9, 185. [CrossRef]

38. Etebari, K.; Hussain, M.; Asgari, S. Identification of microRNAs from Plutella xylostella larvae associated with parasitization by Diadegma semiclausum. Insect Biochem. Mol. Biol. 2013, 43, 309-318. [CrossRef] [PubMed]

39. Piyaphongkul, J.; Pritchard, J.; Bale, J. Heat stress impedes development and lowers fecundity of the brown planthopper Nilaparvata lugens. PLoS ONE 2012, 7, e47413. [CrossRef]

40. Wang, Y.; Chen, J.; Zhu, Y.C.; Ma, C.; Shen, J. Susceptibility to neonicotinoids and risk of resistance development in the brown planthopper, Nilaparvata lugens (Stål) (Homoptera: Delphacidae). Pest Manag. Sci. 2010, 64, 1278-1284. [CrossRef]

41. Zha, W.; Zhou, L.; Li, S.; Liu, K.; Yang, G.; Chen, Z.; Liu, K.; Xu, H.; Li, P.; Hussain, S.; et al. Characterization and comparative profiling of the small RNA transcriptomes in the Hemipteran insect Nilaparvata lugens. Gene 2016, 595, 83-91. [CrossRef]

42. Xue, J.; Zhou, X.; Zhang, C.X.; Yu, L.L.; Fan, H.W.; Wang, Z.; Xu, H.J.; Xi, Y.; Zhu, Z.R.; Zhou, W.W.; et al. Genomes of the rice pest brown planthopper and its endosymbionts reveal complex complementary contributions for host adaptation. Genome Biol. 2014, 15, 521. [CrossRef]

43. Langmead, B.; Salzberg, S.L. Fast gapped-read alignment with Bowtie 2. Nat. Methods 2012, 9, 357-359. [CrossRef] 
44. Kruger, J.; Rehmsmeier, M. RNAhybrid: microRNA target prediction easy, fast and flexible. Nucleic Acids. Res. 2006, 34, W451-W454. [CrossRef]

45. Vikram, A.; Bell, G.W.; Jin-Wu, N.; Bartel, D.P. Predicting effective microRNA target sites in mammalian mRNAs. eLife 2015, 4, e05005.

46. Young, M.D.; Wakefield, M.J.; Smyth, G.K.; Oshlack, A. Gene ontology analysis for RNA-seq: Accounting for selection bias. Gemome Biol. 2010, 11, R14. [CrossRef]

47. Mao, X.; Cai, T.; Olyarchuk, J.G.; Wei, L. Automated genome annotation and pathway identification using the KEGG Orthology (KO) as a controlled vocabulary. Bioinformatics 2005, 21, 3787-3793. [CrossRef]

48. Liao, X.; Xu, P.F.; Gong, P.P.; Wan, H.; Li, J.H. Current susceptibilities of brown planthopper Nilaparvata lugens to triflumezopyrim and other frequently used insecticides in China. Insect Sci. 2021, 28, 115-126. [CrossRef]

49. Whitehorn, P.R.; O'Connor, S.; Wackers, F.L.; Goulson, D. Neonicotinoid pesticide reduces bumble bee colony growth and queen production. Science 2012, 336, 351-352. [CrossRef]

50. Daza, F.F.F.; Roman, G.R.; Rodriguez, M.V.; Vargas, I.A.G.; Heano, H.C.; Cereda, M.P.; Mulet, R.A.C. Spores of Beauveria bassiana and Trichoderma lignorum as a bioinsecticide for the control of Atta cephalotes. Biol. Res. 2019, 52, 51. [CrossRef]

51. Zhang, W.; Chen, J.; Keyhani, N.O.; Zhang, Z.; Li, S.; Xia, Y. Comparative transcriptomic analysis of immune responses of the migratory locust, Locusta migratoria, to challenge by the fungal insect pathogen, Metarhizium acridum. BMC Genom. 2015, 16, 867. [CrossRef]

52. Wang, C.; Wang, S. Insect pathogenic fungi: Genomics, molecular interactions, and genetic improvements. Annu. Rev. Entomol. 2017, 62, 73. [CrossRef]

53. Lu, H.L.; St Leger, R.J. Insect immunity to entomopathogenic fungi. Adv. Genet. 2016, 94, 251-285.

54. Dan, H. Drosophila immunity: Paths and patterns. Curr. Opin. Immunol. 2003, 15, 12-19.

55. Duressa, T.F.; Vanlaer, R.; Huybrechts, R. Locust cellular defense against infections: Sites of pathogen clearance and hemocyte proliferation. Dev. Comp. Immunol. 2015, 48, 244-253. [CrossRef]

56. Kounatidis, I.; Ligoxygakis, P. Drosophila as a model system to unravel the layers of innate immunity to infection. Open Biol. 2012, 2, 120075. [CrossRef]

57. Wang, C.S.; St Leger, R.J. The MAD1 adhesin of Metarhizium anisopliae links adhesion with blastospore production and virulence to insects, and the MAD2 adhesin enables attachment to plants. Eukaryot. Cell 2007, 6, 808-816. [CrossRef]

58. Yu, Y.; Cao, Y.; Xia, Y.; Liu, F. Wright-Giemsa staining to observe phagocytes in Locusta migratoria infected with Metarhizium acridum. J. Invertebr. Pathol. 2016, 139, 19-24. [CrossRef]

59. Keren, A.; Tamir, Y.; Bengal, E.; Keren, A.; Tamir, Y.; Bengal, E. The p38 MAPK signaling pathway: A major regulator of skeletal muscle development. Mol. Cell. Endocrinol. 2006, 252, 224-230. [CrossRef]

60. Wang, M.; Wang, Q.; Wang, Z.; Wang, Q.; Pan, Y. The molecular evolutionary patterns of the insulin/FOXO signaling pathway. Evol. Bioinform. 2013, 9, 1-16. [CrossRef]

61. Xu, J.; Xu, X.; Li, S.; Wang, S.; Xu, X.; Zhou, X.; Yu, J.; Yu, X.; Shakeel, M.; Jin, F. Genome-wide profiling of Plutella xylostella immunity-related miRNAs after Isaria fumosorosea infection. Front. Physiol. 2017, 8, 1054. [CrossRef] 